\title{
Combined phototherapeutic keratectomy and therapeutic contact lens for recurrent erosions in bullous keratopathy
}

\author{
Pei-Yu Lin, Chih-Chiau Wu, Shui-Mei Lee
}

\begin{abstract}
Aims-To evaluate the therapeutic effects of excimer laser phototherapeutic keratectomy (PTK) combined with therapeutic contact lens for painful recurrent corneal erosions (RCE) secondary to bullous keratopathy (BK) not suitable for penetrating keratoplasty.

Methods-Excimer laser PTK was performed prospectively in eight eyes with painful RCE due to BK visually expecting no benefit from penetrating keratoplasty. After mechanical removal of the epithelium, the corneas were ablated with 50 pulses in the central $6.5 \mathrm{~mm}$ zone (ablation rate $0.25 \mu \mathrm{m}$ per pulse) and another 200 pulses for polishing the periphery. After PTK, therapeutic contact lenses were applied for 3 months. The mean follow up period after PTK was 10.9 months (ranging from 6 to 15 months).

Results-All patients experienced relief of their pain symptoms after the epithelium healed. Only one patient complained of occasional stinging pain with intermittent recurrence of small bullae. He refused a second treatment because the pain was much less than that before the surgery and quite tolerable. No infection or other complications were noted.

Conclusion-PTK with deeper ablation and adjunctive therapeutic contact lens is an easy to perform and effective treatment with less recurrence rate for patients with $B K$ and poor visual potential. (Br F Ophthalmol 2001;85:908-911)
\end{abstract}

National Yang Ming

University,

Department of

Ophthalmology, Taipei

Veterans General

Hospital, Taiwan, ROC

P-Y Lin

C-C Wu

S-M Lee

Correspondence to:

Pei-Yu Lin, MD

Department of

Ophthalmology, Taipei

Veterans General Hospital,

201, Sec 2, Shih-Pai Road,

Taipei, Taiwan, ROC

pylin@vghtpe.gov.tw

Accepted for publication 21 February 2001

The best treatment of choice for bullous keratopathy (BK) with painful recurrent corneal erosions (RCE) is penetrating keratoplasty. But in cases not suitable for penetrating keratoplasty or the visual potential is poor the treatment goal is to relieve patients of pain with methods including Gunderson's conjunctival flap surgery, ${ }^{12}$ bandage contact lens, ${ }^{34}$ epikeratophakia, ${ }^{5}$ anterior stromal puncture, ${ }^{6}$ excimer laser phototherapeutic keratectomy (PTK), ${ }^{78}$ annular keratotomy, ${ }^{9}$ and amniotic membrane transplantation. ${ }^{10}$ PTK has been successfully used in the treatment of $\mathrm{RCE}^{11-20}$ caused by varied aetiologies. The recurrence rate ranged from $0 \%$ to $26 \%$ after a single treatment. In 1995 Thomann et al reported using PTK to treat patients with RCE due to $\mathrm{BK}$ with promising effect. However, in around $77 \%$ of the patients, bullae persisted weeks after the treatment. Although bullae became rare in most patients after 1-2 months, in five of $13(38.5 \%)$ patients, a second treatment was necessary because of persistent pain. In 1994, we performed PTK with ablation depth of 5 $\mu \mathrm{m}$ after removal of the epithelium in two cases of RCE due to BK. After initial epithelial healing and relief of symptoms in 4 days, both of them showed recurrence of bullae and epithelial erosion in 10 days (Fig 1). The underlying endothelial decompensation was thought to be the aetiology of recurrent bullae formation. And because of the subepithelial fluid accumulation, the process of epithelial adhesion to the Bowman's membrane was interrupted, which was probably one of the reasons for the higher recurrence rate.

It is generally accepted that the ablation depth of PTK for RCE is limited within the Bowman's layer to prevent stromal haze formation. But in cases of BK with poor visual potential, the treatment goal is to relieve pain. In clinical experience the epithelium-stroma adhesion with haze formation seen in photorefractive keratectomy (PRK) seldom gives rise to RCE. So PTK with ablation depth beyond the Bowman's layer may probably promote tighter epithelial adhesion and consequently will provide benefit if not disturbing the already poor vision. This study was designed to

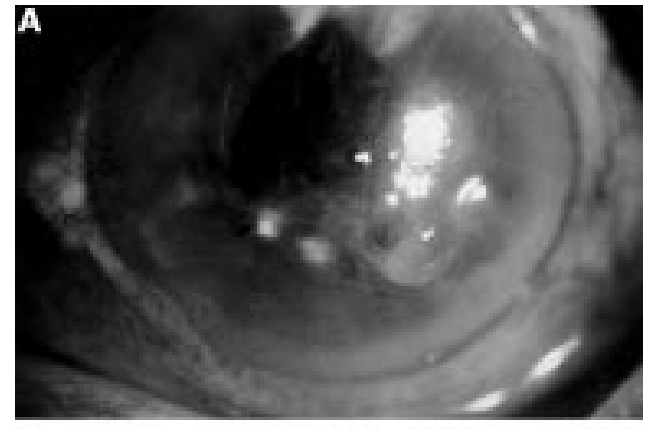

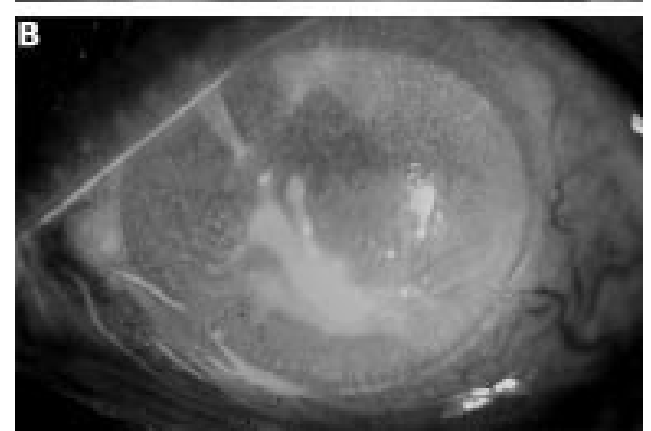

Figure 1 (A) Bullous keratopathy before phototherapeutic keratectomy (PTK). (B) Recurrence of epithelial erosion 10 days after PTK without using therapeutic contact lens shown with fluorescent stain. 
Table 1 Patient data

\begin{tabular}{lllllll}
\hline Patient & Age & Sex & $\begin{array}{c}\text { Follow up period } \\
\text { (months) }\end{array}$ & Associated diseases & Preop VA & Postop VA \\
\hline 1 & 72 & M & 15 & Glaucoma & NLP & NLP \\
2 & 68 & M & 14 & Glaucoma & HM & CF \\
3 & 63 & F & 13 & RD & HM & HM \\
4 & 61 & F & 12 & Glaucoma & LP & HM \\
5 & 66 & M & 6 & ARMD & HM & CF \\
6 & 67 & F & 12 & Glaucoma & CF & CF \\
7 & 81 & F & 9 & PDR & CF & CF \\
8 & 74 & M & 6 & Glaucoma & HM & HM \\
\hline
\end{tabular}

evaluate the effect of PTK with deeper ablation and adjunctive postoperative therapeutic contact lens to prevent early bullae recurrence in the treatment of painful RCE due to BK.

\section{Patients and methods}

Between April 1999 and January 2000 we performed PTK on eight eyes of eight patients with recalcitrant painful $\mathrm{RCE}$ due to $\mathrm{BK}$ of varying aetiologies (Table 1 ). The mean follow up period was 10.9 (ranging from 6 to 15) months. After thorough discussion with the patients, corneal transplantation was not considered because of their poor visual potential. Every patient had a complete ophthalmic examination before the treatment and was followed up regularly postoperatively.

All therapy was performed with the Summit SVS Apex Plus excimer laser (193 nm, 180 $\mathrm{mJ} / \mathrm{cm}^{2}$, ablation rate $0.25 \mu \mathrm{m}$ per pulse, pulse frequency $10 \mathrm{~Hz}$ ) using PTK mode. Under topical anaesthesia, the whole epithelium except that close to the limbus was removed easily with a No 64 Beaver blade or Weckcell. The central $6.5 \mathrm{~mm}$ optic zone was ablated with 50 pulses. Then the already ablated area was protected with $2 \%$ methylcellulose. The peripheral ring was polished with another 200 pulses of diameter $2-3 \mathrm{~mm}$ in an annular fashion by rotating the patient's head smoothly.
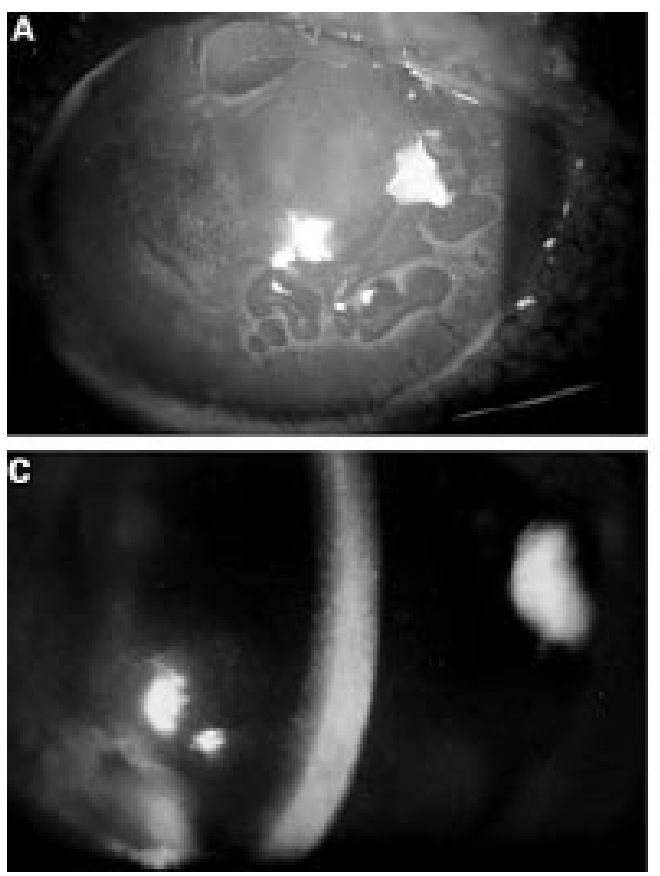

Figure 2 (A) Case 8. Bullous keratopathy before PTK shown with fluorescent stain. (B) Six months after PTK. No recurrence of bullae. Anterior stromal haze similar to that seen after photorefractive keratectomy (PRK) for myopia was shown. (C) Case 4. Anterior stromal haze persisted without recurrence of bullae 1 year after PTK. (D) Case 1. Intermittent recurrence of small bullae after removal of therapeutic contact lens.

After PTK, a therapeutic contact lens was applied immediately and exchanged every $2-3$ weeks for 3 months together with topical antibiotics $(0.25 \%$ chloramphenicol). Nonpreserved artificial tears (Refresh, Allergan) and antiglaucoma medications were used when necessary. No topical corticosteroids were given. All patients were treated only once.

\section{Results}

All patients experienced relief of their pain after the epithelium healed, which took 3-4 days. No recurrence of bullae or pain was observed in all patients with the contact lens in position and remained so in seven patients after removal of the contact lens. Anterior stromal haze similar to that seen after PRK for myopia was noted after 2-3 months. After removal of the contact lens, one patient complained of occasional stinging pain with intermittent recurrence of small bullae (Fig 2). $\mathrm{He}$ refused a second treatment because the pain was much less than that before the surgery and was quite tolerable.

Although all patients had very poor visual potential, slight improvement in vision was shown in three patients (Table 1). No patient experienced deterioration of vision. Two patients complained of a sticky sensation that could be partially relieved with lubricant eye drops. No infection or other complications were noted.

\section{Discussion}

Three issues are involved in the treatment of RCE due to BK with PTK. Firstly, should the treatment zone be restricted to the affected area or extended to the entire cornea? Secondly, should the ablation depth be limited
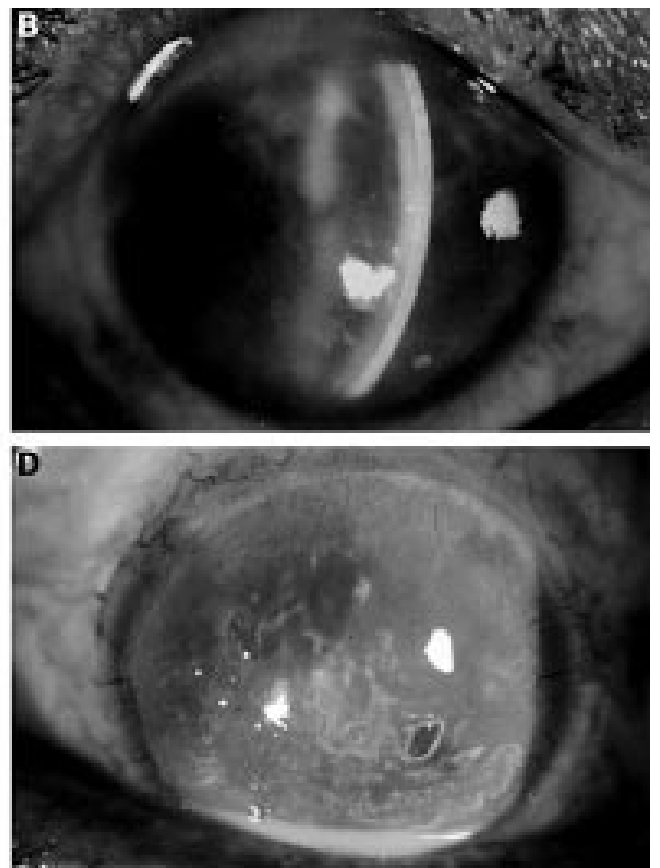
within the Bowman's layer? Thirdly, should therapeutic contact lenses be used and for how long?

There are several reports on the treatment of RCE with PTK. ${ }^{11-20}$ Most of them restricted the treatment zone to the affected area. For our cases of RCE, the whole epithelium was very loosely attached to the underlying Bowman's layer. Then, should recalcitrant RCE be treated extensively? Kaplan-Messas et $a l^{1}$ reported a study that compared a focal mode of PTK treatment with a diffuse mode for RCE. Two eyes with focal PTK, but no eye with diffuse PTK had recurrent erosions after a mean follow up of 8.0 and 9.0 months, respectively. Kremer et $a l^{22}$ combined PRK and PTK to treat 16 myopic eyes with recalcitrant RCE. Following total epithelial scraping, PRK was performed at a central $6.0 \mathrm{~mm}$ zone. Then, confluent $3.0 \mathrm{~mm}$ zones of PTK were ablated at a depth of $6.0 \mu \mathrm{m}$, surrounding the zone of PRK. There was no recurrence during the follow up period, which ranged from 26 to 42 months. In Thomann et al's study ${ }^{7}$ of PTK for RCE in BK, only the bullous area was treated. They did not mention whether the recurrent bullae were located inside or outside the treatment zone. But for BK, the bullae will change position from time to time. It is suggested that $\mathrm{RCE}$ especially in $\mathrm{BK}$ is a diffuse disease, and therefore extensive ablation may be more desirable for prevention of recurrence.

In order to prevent hyperopic shift and corneal haze, the ablation depths of PTK for RCE are usually limited within the Bowman's layer. But for patients with BK with poor visual potential, the treatment goal is to relieve pain by enhancing epithelial adhesion. In the patients who are re-treated after PRK with regress and haze, the epithelium appears to be more firmly adherent to the underlying ablated zone and the anterior stromal surface becomes more irregular. ${ }^{14}{ }^{23}$ Marshall et $a l^{24}$ noted discontinuities of the basement membrane in the laser ablated area with the resultant microexcursion of stroma anteriorly and epithelium posteriorly. The solid haze that developed in the anterior stroma after PRK or PTK is due to collagen deposits produced by myofibroblast. ${ }^{25}{ }^{26}$ Although no conclusion can be drawn from these observations concerning the strength of adhesion between epithelium and stroma in the absence of the Bowman's layer, clinical experience shows that superficial keratectomy rarely gives rise to RCE postoperatively. ${ }^{27}$ Accordingly, one might expect at least normal, if not stronger, strength of adhesion between the epithelium and the stroma with the Bowman's layer ablated and haze developed.

It is suggested that at least 2 months are required for the treatment of RCE. ${ }^{28}$ Animal studies show that the adhesion complex between corneal epithelium and stroma is restored 6-8 weeks after injury. ${ }^{27} 290$ In Thomann et al's study, ${ }^{78} 77 \%$ of patients who received PTK for RCE due to BK showed persistence of bullae for 1-2 months postoperatively. This coincides with the time for adhesion complex formation. Because of the underlying endothelial decompensation, fluid will re-accumulate beneath the epithelium after the epithelium is healed but not yet adherent to the stroma. Application of therapeutic contact lens during this period can prevent bullae recurrence ${ }^{34}$ that might interfere with adhesion complex formation. According to SundarRaj et al's report, ${ }^{31}$ for rhesus monkeys receiving excimer laser keratectomy, the re-establishment of a nearly continuous anchoring fibril zone was evident after 12 weeks. Our patients wore therapeutic contact lenses for 3 months and no RCE was suffered when the contact lenses were in place. However, the exact time required for human adhesion complex formation after excimer laser ablation, especially in cases of $\mathrm{BK}$, remains to be explored. Because most of our patients had a history of multiple surgery and consequently unstable tear film, long term contact lens wearing may lead to the hazard of infectious keratitis. So we limit the contact lens wearing time to 3 months and none of our patients had infection.

This preliminary report demonstrates that the methods we used for relieving symptoms of $\mathrm{BK}$ is easy to perform and highly effective with low recurrence rate. However, longer follow up is required for evaluation of the long term effectiveness. And more research, especially ultrastructural studies, is needed before any conclusion can be drawn about the epithelial adhesion strength in conditions of different excimer laser ablation depth and the effects of therapeutic contact lens on anchoring complex formation for cases of BK.

1 Smith R. Surgical relief of bullous keratopathy (Gunderon's operation). Trans Ophthalmol Soc UK 1965;85:307 16.

2 Alino AM, Perry HD, Kanellopoulos AJ, et al. Conjunctival flaps. Ophthalmology 1998;105:1120-3.

3 Gasset AR, Kaufman HE. Bandage lenses in the treatment of bullous keratopathy. Am f Ophthalmol 1971;72:376-80.

4 Ruben M. Soft contact lens treatment of bullous keratopathy. Trans Ophthalmol Soc UK 1975;95:75-8.

5 Roat MI, Hiles DA. Epikeratophakia for control of pediatric bullous keratopathy. F Cataract Refract Surg 1987;13:5962.

6 Gormier G, Brunette I, Boisjoly HM, et al. Anterior stromal punctures for bullous keratopathy. Arch Ophthalmol 1996; punctures for

7 Thomann U, Meier-Gibbons F, Schipper I. Phototherapeutic keratectomy for bullous keratopathy. $\mathrm{Br} \mathcal{F}$ Ophthalmol 1995;79:335-8

8 Thomann U, Niesen U, Schipper I. Successful phototherapeutic keratectomy for recurrent erosions in bullous keratopathy. F Refract Surg 1996;12:S290-2.

9 Koenig SB. Annular keratotomy for the treatment of painful bullous keratopathy. Am f Ophthalmol 1996;121:93-4.

10 Pires RTF, Tseng SCG, Prabhasawat P, et al. Amniotic membrane transplantation for symptomatic bullous keratopathy. Arch Ophthalmol 1999;117:1291-7.

11 Dausch D, Landesz M, Klein R, et al. Phototherapeutic keratectomy in recurrent corneal epithelial erosion. Refract Corneal Surg 1993;9:419-24.

12 Förster W, Grewe S, Atzler U, et al. Phototherapeutic keratectomy in corneal diseases. Refract Corneal Surg 1993; 9(suppl):85-90.

13 Tuunanen TW, Tervo TM. Excimer laser phototherapeutic keratectomy for corneal diseases; a follow-up study. CLAO f 1995;21:67-72.

14 O'Brart DPS, Kerr Muir MG, Marshall J. Phototherapeutic keratectomy for recurrent corneal erosions. Eye 1994;8: 378-83.

15 John ME, Van Der Karr MA, Noblitt RL, et al. Excimer laser phototherapeutic keratectomy for treatment of recurrent corneal erosion. F Cataract Refract Surg 1994;20:17981 .

16 Hersh PS, Burnstein Y, Carr J, et al. Excimer laser phototherapeutic keratectomy: surgical strategies and clinical outcomes. Ophthalmology 1996;103:1210-22.

17 Förster W, Atzler U, Ratkay I, et al. Therapeutic use of the 193-nm excimer laser in corneal pathologies. Graefes Arch
Forster W, Atzler U, Ratkay I, et al. Therapeutic use of the Clin Exp Ophthalmol 1997;235:296-305. 
18 Morad Y, Haviv D, Zadok D, et al. Excimer laser phototherapeutic keratectomy for recurrent corneal ero-
sion. $\mathcal{F}$ Cataract Refract Surg 1998;24:451-5.

19 Jane S, Austin DJ. Phototherapeutic keratectomy for treatment of recurrent corneal erosion. F Cataract Refract Surg 1999;25:1610-4

20 Cavanaugh TB, Lind DM, Cutarelli PE, et al. Phototherapeutic keratectomy for recurrent erosion syndrome in anterior basement membrane dystrophy. Ophthalmology 1999 106:971-6.

21 Kaplan-Messas A, Assouline M, Saragoussi JJ, et al. Diffuse versus focal photoablation for recurrent epithelial erosion. ARVO Abstract No 2646. Invest Ophthalmol Vis Sci 1996;37:S574.

22 Kremer I, Blumenthal M. Combined PRK and PTK in myopic patients with recurrent corneal erosion. $\mathrm{Br} \mathcal{F}$ Ophthalmol 1997;81:551-4.

23 Kapadia MS, Meisler DM, Wilson SE. Epithelial removal with the excimer laser (laser-scrape) in photorefractive keratectomy retreatment. Ophthalmology 1999;106:29-34

24 Marshall J, Trokel SL, Rothery S, et al. Long-term healing of the central cornea after photorefractive keratectomy
using an excimer laser. Ophthalmology 1988;95:1411-21.
25 Wu WCS, Stark WJ, Green WR. Corneal wound healing after 193-nm excimer laser keratectomy. Arch Ophthalmol 1991;109:1426-32.

26 Fagerholm P. Wound healing after photorefractive keratectomy. F Cataract Refract Surg 2000;26:432-47.

27 Khodadoust AA, Silverstein AM, Kenyon KR, et al. Adhesion of regenerating corneal epithelium: the role of basement membrane. Am F Ophthalmol 1968;65:33948.

28 Kenyon KR. Recurrent corneal erosion: pathogenesis and therapy. Int Ophthalmol Clin 1979;19:169-95.

29 Gipson IK, Supurr-Michaud SJ, Tisdale AS. Hemidesmosomes and anchoring fibril collagen appear synchronously during development and wound healing. Dev Biol 1988; 126:235-62.

30 Gipson IK, Supurr-Michaud SJ, Tisdale AS, et al. Reassembly of the anchoring structures of the corneal epithelium during wound repair in the rabbit. Invest Ophthalmol Vis $\mathrm{Sci}_{\mathrm{C}}$ 1989;30:425-34.

31 SundarRaj N, Geiss M, Fantes F, et al. Healing of excimer laser ablated monkey corneas: an immunohistochemical evaluation. Arch Ophthalmol 1990;108:1604-10.

\section{Contributors please note:}

Communications from all countries except the UK and Republic of Ireland should be sent to Professor C Hoyt, Editor, British fournal of Ophthalmology, University of California, Department of Ophthalmology, 10 Kirkham Street, K 301, San Francisco, CA 94143-0730, USA (tel: 001415 502-6871; fax: 001415 514-1521).

Manuscripts from the UK and the Republic of Ireland should be sent to Professor Andrew Dick, UK Editor, British fournal of Ophthalmology, Division of Ophthalmology, University of Bristol, Lower Maudlin Street, Bristol BS1 2LX (tel: +44 (0) 0117 929-4496; fax: +44 (0) 117 929-4607). 